\title{
Recommendations for the follow-up care of female breast cancer survivors: a guideline of the Spanish Society of Medical Oncology (SEOM), Spanish Society of General Medicine (SEMERGEN), Spanish Society for Family and Community Medicine (SEMFYC), Spanish Society for General and Family Physicians (SEMG), Spanish Society of Obstetrics and Gynecology (SEGO), Spanish Society of Radiation Oncology (SEOR), Spanish Society of Senology and Breast Pathology (SESPM), and Spanish Society of Cardiology (SEC)
}

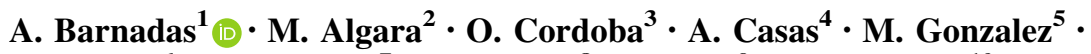 \\ M. Marzo $^{6}$ - A. Montero ${ }^{7}$ - M. Muñoz ${ }^{8}$ A. Ruiz ${ }^{9}$ F. Santolaya ${ }^{10}$. \\ T. Fernandez ${ }^{11}$
}

Received: 16 October 2017/Accepted: 17 October 2017/Published online: 14 November 2017

(c) The Author(s) 2017. This article is an open access publication

\begin{abstract}
The increased incidence and decreased mortality of breast cancer have produced an increased number of breast cancer survivors. The type of sequelae and comorbidities that these patients present call for a collaborative
\end{abstract}

A collaborative project of:

A. Barnadas: Sociedad Española de Oncología Médica (SEOM).

M. Algara: Sociedad Española de Senología y Patología Mamaria (SESPM).

O. Cordoba: Sociedad Española de Obstetricia y Ginecología (SEGO).

A. Casas: Sociedad Española de Oncología Médica (SEOM).

M. Gonzalez: Sociedad Española de Medicina General (SEMERGEN).

M. Marzo: Sociedad Española de Medicina Familiar y Comunitaria (SEMFYC).

L. Montero: Sociedad Española de Oncología Radioterápica (SEOR).

M. Muñoz: Sociedad Española de Oncología Médica (SEOM).

A. Ruiz: Sociedad Española de Oncología Médica (SEOM).

F. Santolaya: Sociedad Española de Médicos Generales y de Familia (SEMG). follow-up by hospital-based specialized care and primary care. In this document, we present a guideline drafted and agreed among scientific societies whose members care for breast cancer survivors. The purpose of this guideline is to

T. Fernandez: Sociedad Española de Cardiología (SEC).

A. Barnadas

abarnadasm@santpau.cat

1 Department of Medical Oncology, Hospital de la Santa Cruz y San Pablo, Barcelona, Spain

2 Department of Radio-oncology, Parc de Salut Mar, Barcelona, Spain

3 Department of Gynecology and Obstetrics, Hospital de la Vall d'Hebrón, Barcelona, Spain

4 Department of Medical Oncology, Hospital Virgen del Rocío, Seville, Spain

5 Montesa Healthcare Center, Servicio Madrileño de Salud, Madrid, Spain

6 Catalonian Health Institute, Generalitat de Catalunya, Barcelona, Spain

7 Department of Radio-oncology, Hospital Universitario HM Sanchinarro, Madrid, Spain

8 Department of Medical Oncology, Hospital Clínic Barcelona, Barcelona, Spain 
achieve the shared and coordinated follow-up of these patients by specialized care and primary care professionals. In it, we review the health issues derived from the treatments performed, with recommendations about the therapeutic approach to each of them, as well as a proposal for joint follow-up by primary and specialized care.

Keywords Breast cancer - Treatment chronic side effects sequelae $\cdot$ Follow-up guidelines $\cdot$ Primary care . Specialized care

\section{Introduction}

Breast cancer is the most common malignancy in the female population, with a cure rate that exceeds $80 \%$. The gradual increase in incidence, associated with an aging population and the implementation of screening programs, together with lower mortality rates, account for an increased number of patients who are breast cancer survivors (BCSs) [1].

BCSs often have a life that is conditioned by the sequelae or morbidities related to treatment of the disease and, despite the high cure rates, many of the patients are no longer able to enjoy the quality of life achieved by women in our society. The treatments administered can leave physical, psychological, and psychosocial sequelae that may manifest or persist even years after having completed treatment and can interfere with their well-being and reincorporation into ordinary social and occupational activities [2].

Breast cancer is not a single disease, and treatment options depend on each tumor's biology and behavior, as well as on each patient's characteristics. Among patient characteristics, we must mention age, overall health status, and menopause status as being highly important factors when defining individualized treatment and preventing certain treatment-derived complications [3].

There are three essential aims that BCS follow-up pursues: (1) early diagnosis of relapses, (2) minimizing the impact of sequelae and complications derived from breast cancer diagnosis and treatment, and (3) encouraging healthcare and preventive measures to promote well-being and decrease risks to their health. Thus, a better quality of life might be achieved by helping BCSs to reintegrate as

\footnotetext{
9 Department of Medical Oncology, Instituto Valenciano de Oncología, Valencia, Spain

10 Ciudad San Pablo Healthcare Center, Servicio Madrileño de Salud, Madrid, Spain

11 Department of Cardiology, Hospital La Paz Madrid, Madrid, Spain
}

fully as possible into the various areas of their lives, i.e., family, work, and social activities $[4,5]$.

The need for specialized hospital-based care (SC) and primary care (PC) to share BCS patient follow-up activities has become evident in recent years and requires effective coordination. This shared, coordinated follow-up must ensure that the three previously named goals are met. The primary care physician plays a prominent role in detecting relapses and second neoplasms, dealing with late-onset effects of cancer treatment, managing comorbidity, psychological care, promoting healthy lifestyles, and recommending health prevention strategies, as well as normalizing the healthcare of patients who have been cured of breast cancer. Furthermore, BCSs continue to benefit from receiving care by the hospital-based specialist, especially during the first 5 years of follow-up [6-9].

In this document, we present a guideline that has been drafted and agreed among different scientific societies whose members care for BCSs. The purpose of this guideline is to archive that the follow-up of these patients will be shared, collaborative, and coordinated among SC and PC professionals.

\section{Treatment-derived health problems}

As previously noted, the therapies administered may entail different sequelae that can translate into impaired quality of life for women who have overcome breast cancer. Some sequelae are late onset. Identifying these issues and correcting them can improve adaptation to daily life [9]. On the other hand, certain adverse effects may condition adherence to prolonged hormone therapy. It is also important to know whether the patients are receiving other medications or alternative therapies that might interfere with the activity of endocrine therapy. The PC physician is best suited to detect and control these side effects.

The side effects that call for special attention according to their frequency are as follows: lymphedema, effects derived from ovarian failure and menopause-related symptoms, overweight, cardiotoxicity, other vascular toxicities, neurotoxicity, ocular toxicity, cognitive impairment, skin alterations, and the risk of second neoplasms. The characteristics of these side effects and management recommendations are summarized in Table 1.

In addition, there are general recommendations that must be followed $[8,9]$ :

- Overweight avoidance Weight gain has been associated with a worse treatment response and greater risk of relapse.

- Healthy diet and exercise Epidemiological studies have proven a benefit for patients following a low-fat diet 


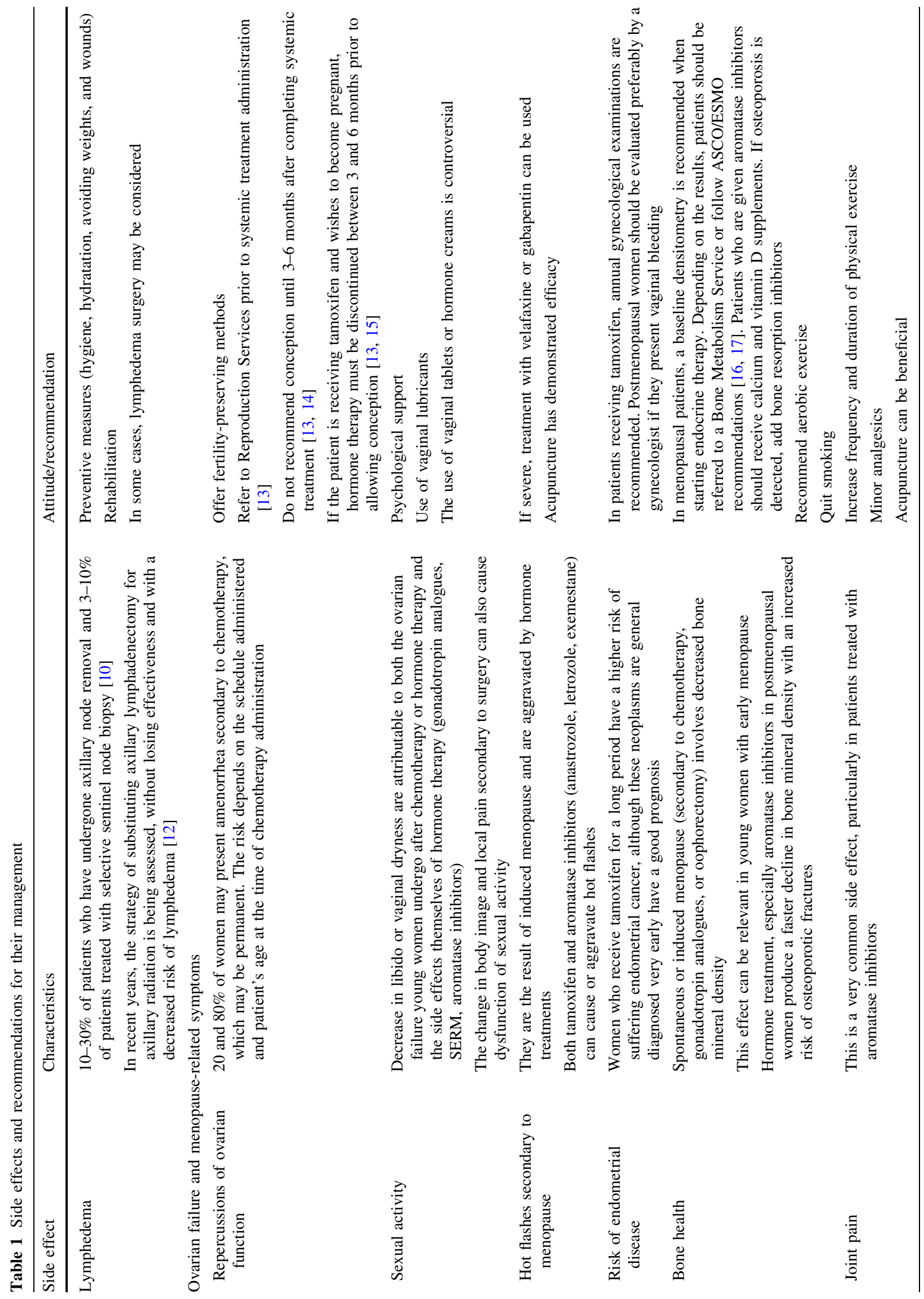




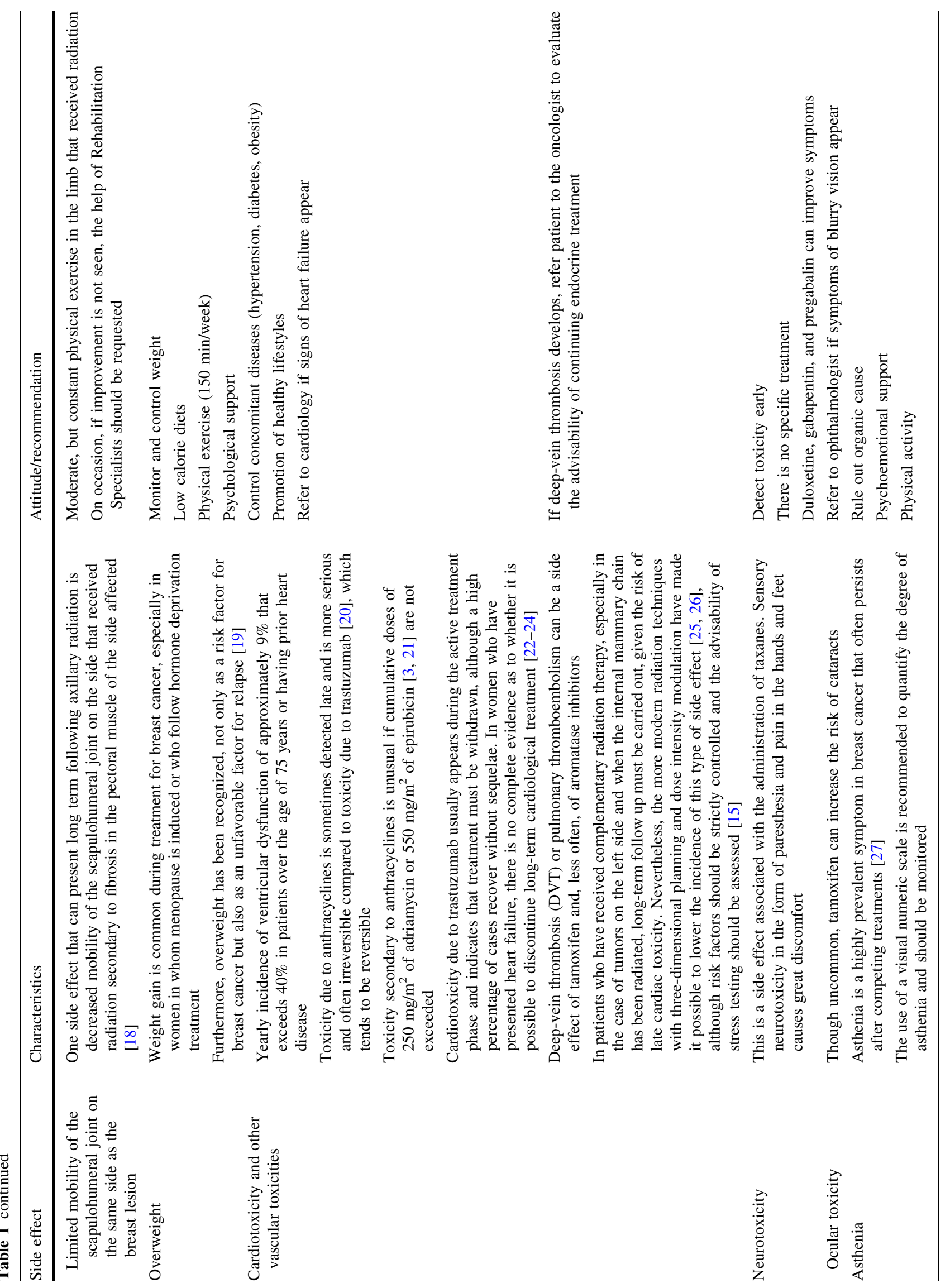


together with at least 150 min of vigorous physical activity per week [10]. The recommended diet is high in fresh fruits, vegetables, and legumes (at least two pieces of fruit per day); patients are also recommended to lower their intake of red meat (to 1-2 times per week) and processed meats and increase consumption of blue fish, olive oil use and consume dairy products, as well as take advantage of all the elements comprising a Mediterranean diet.

- Smoking avoidance

- Moderate alcohol intake It is recommended that women abstain from drinking more than $20 \mathrm{~g}$ of alcohol per day. The following beverages equal $20 \mathrm{~g}$ of alcohol: $250 \mathrm{ml}$ of beer, one glass of red wine $(150 \mathrm{ml})$, or a quarter of a glass $(25 \mathrm{ml})$ of a higher grade liquor (e.g., gin, whisky, anise, and tequila).

- Use of complementary therapies Some of these therapies could interfere with patient treatment. Acupuncture must be properly performed and with necessary aseptic measures to minimize the risk of infection. Complementary or integrative therapies cannot substitute for a specific antitumor treatment.

- Awareness of symptoms that indicate possible relapse or second tumors The following symptoms should be monitored: persistent bone pain that increases with movement and fails to remit with rest, persistent cough, dyspnea, asthenia, anorexia, or unexplained weight loss, vaginal bleeding in postmenopausal women, change in intestinal rhythm, rectal bleeding, or persistent headache or other neurological deficit. Thus, an early diagnosis can be made.

- Confirmation of compliance with antiestrogenic hormone therapy Control and positive reinforcement to maintain the prescribed treatment even over prolonged periods (5-10 years).

- Return to work Support and guidance appropriate to the patient's stage of evolution. In the case of complementary treatment, it is recommended that patients wait for a reasonable time so that they can recover from the side effects of treatment.

- Active alertness of the appearance of symptoms suggestive of heart disease.

\section{Proposal of joint primary care and specialized care follow-up (Table 2)}

Studies conducted thus far have revealed that radiological testing is not useful, except for yearly mammograms and that a PC physician or nurse can conduct follow-up if they are motivated and trained to care for the complications or morbidities that BCS present. Patient satisfaction will 
Table 2 Proposed follow-up together with primary care

\begin{tabular}{|c|c|c|}
\hline Risk group & Definition & Recommendation \\
\hline Low risk & $\begin{array}{l}\text { Hormone-sensitive tumor } \\
\text { Size } \leq 2 \mathrm{~cm} \text { (category pT1) } \\
\text { No axillary metastases } \\
\text { Low risk according to genomic platform } \\
\text { Carcinoma "in situ" }\end{array}$ & $\begin{array}{l}\text { Clinical check-up every } 6 \text { months, alternating with primary care } \\
\text { (PC) for } 5 \text { years } \\
\text { After } 5 \text { years, only PC will be responsible for check-ups } \\
\text { Yearly mammogram }\end{array}$ \\
\hline $\begin{array}{l}\text { Intermediate } \\
\text { risk }\end{array}$ & $\begin{array}{l}\text { Hormone-sensitive tumor } \\
\text { Size between } 2 \text { and } 5 \mathrm{~cm} \text { (category pT2) } \\
\text { No nodal metastases or axillary metastases involving } \\
\text { between } 1 \text { and } 3 \text { nodes } \\
\text { Intermediate risk according to genomic platform }\end{array}$ & $\begin{array}{l}\text { Check-up every } 4 \text { months together with PC for the first } 2 \text { years } \\
\text { Every } 6 \text { months until the fifth year } \\
\text { Only PC will be responsible for check-ups after that } \\
\text { Yearly mammogram }\end{array}$ \\
\hline High risk & $\begin{array}{l}\text { Tumor not expressing hormone receptors } \\
\text { Tumor with HER } 2 \text { amplification } \\
\text { High risk tumor according to genomic platform } \\
\text { Tumor with metastases in more than } 3 \text { axillary nodes } \\
\text { Tumor treated with neoadjuvant therapy } \\
\text { Locally advanced tumor }\end{array}$ & $\begin{array}{l}\text { Check-up every } 4 \text { months together with PC for } 5 \text { years } \\
\text { After } 5 \text { years, every } 6 \text { months together with PC until } 10 \text { years } \\
\text { Only PC will be responsible for check-ups after that } \\
\text { Yearly mammogram }\end{array}$ \\
\hline
\end{tabular}

At every visit, the following should be performed: (i) Complete anamnesis evaluating the presence of comorbidities. (ii) Evaluation of hormone treatment compliance (whenever prescribed). (iii) Detection of side effects. (iv) Physical examination of the mammary glands, rib cage, or area of breast reconstruction and lymph node chain. (v) Foster a healthy lifestyle

depend more on how they are treated than on where followup is undertaken. Studies have also concluded that relapses are detected similarly in PC or SC and that there are no differences in overall survival with any of the different follow-up schemes (with imaging studies and tumor markers compared with history, breast examination, and yearly mammogram), if the patient is guaranteed access to healthcare services in the presence of a symptom or sign of alarm [11].

However, long-term survivors who have overcome breast cancer require outstanding coordination and communication between PC and SC. It is proposed that patients already treated in the hospital be classified into three groups: (1) low risk; (2) intermediate risk, and (3) high risk. Table 2 summarizes the management recommendations coordinated between PC and SC.

Follow-up visits of female BCSs should include the following:

- History aimed at ruling out warning signs of relapse or the presence of sequelae, comorbidities, or second neoplasms.

- Adherence to adjuvant endocrine therapy when indicated.

- A physical examination that includes examination of the breasts and adjacent node regions.

- Bilateral, yearly mammograms in two projections, after conservative surgery of the breast or if the breast has been reconstructed. Annual follow-up visits will be maintained throughout their lifetime because these patients, unlike the healthy population who undergo biannual mammograms in screening campaigns, have a $5-10 \%$ probability of developing local relapse or a second neoplasm within 10 years post-treatment; this higher risk remains throughout their entire lives. Mammograms can be performed within the scope of PC or with the aid of the specialist in Obstetrics and Gynecology.

- Recommendations for prevention and health promotion.

\section{Role of the primary care physician}

More and more women who have had breast cancer are being cared for in primary care. Optimal care by the PC physician includes the prevention, detection of relapses and possible second neoplasms, care for comorbidities, and the approach to late-onset effects of cancer treatment. It is also up to the PC physician to refer all women who have had breast cancer and present an accumulation of cases of cancer in the family to the reference Genetic Counseling Centers. The criteria for reference to a Genetic Counseling Center are as follows: having one or more first- or seconddegree relatives with a breast or ovarian tumor under the age of 50; having a relative with bilateral breast tumors, having a male relative with breast cancer; having a relative with breast cancer with a triple-negative phenotype and less than 60 years of age [10]. Patients should also be referred to these centers when colon cancer is detected in 
different members of the family under the age of 50 at presentation.

Follow-up of BCS calls for a multidisciplinary approach and excellent coordination and communication between PC and SC. The oncologist should facilitate a case report when initiating and completing treatment; this report should include the type and clinical status of the tumor, treatment intent, treatments received, and toxicities that may have arisen during treatment. This information is fundamental to elaborating an individualized care plan that makes appropriate follow-up possible.

Below is the proposed minimum content that would be advisable to include in the report issued by $\mathrm{SC}$ to share patient information with PC:

\section{Initial oncological report}

1. Disease debut (symptom duration, origin [population screening programs, fast track diagnostics, PC physician, others]).

2. Diagnostic testing (imaging studies performed to determine the diagnosis, pathology results of biopsy with immunohistochemical report, clinical TNM).

3. Surgical procedure (if performed, and postoperative TNM).

4. Extension study, prognostic and predictive factors, results of the genomic study of the risk of relapse (if performed).

5. General treatment approach and anticipated date of initiation Medical Oncology's treatment prescription:
(a) Drugs
(b) Sequence of administration. Courses
(c) Anticipated duration.

6. Radiation treatment approach (when applicable):

(a) Volumes to be treated, total dose, and fractioning.

(b) Radiotherapy technique: 3D, IMRT, partial radiation, intraoperative radiation, source, and energy.

7. Prevention guidelines considering possible side effects of treatment.

8. Report if patient is participating in a Clinical Trial.

9. Estimation of time off work Consideration must be paid as to whether the time off work has to do with the characteristics of the workplace, associated risks, and compatibility with the degree of functioning following treatment.

10. Date of the next visit to SC. In some Autonomous Communities, the PC physician can consult them, but not in all of them.

\section{Report upon completion of the initial phase of treatment}

Once the initial stage of treatment is completed (surgery, treatment with chemotherapy, and/or targeted drugs and radiotherapy), after the first 6-15 months, a new stage opens. This period is no less important than the diagnostic stage, given the uncertainty surrounding the quality and continuity of life, during which information about the patient's status must be shared again with PC physicians.

1. Regarding clinical situation during the initial stage of treatment.

(a) Full report that includes the previously listed items (points 1, 2, 3, and 4);

(b) All treatments received: radiotherapy, hormone therapy, or biological therapy, and if the patient has been included in a clinical trial. Treatment duration and related side effects and their treatment prevention (points 5 and 6);

(c) Information about the risk of cardiotoxicity and type of cardiovascular monitoring undertaken;

(d) Overall evolution;

(e) Information regarding schedules for follow-up: tests and timing, outline of visits with SC.

2. Regarding clinical recommendations

(a) Warning signs that a new appointment should be set up with SC;

(b) Specific approach to lymphedema: when, how, and who to refer to;

(c) Motor rehabilitation if necessary and recommendations regarding physical exercise;

(d) Specific approach toward side effects of hormone medication. Recommendations for the prevention/treatment of osteoporosis and related side effects;

(e) Control of mammary implants/expander/prosthetic replacement, and related events;

(f) Dietary recommendations;

(g) Special considerations regarding patients' health issues and comorbidities, and

(h) Complementary therapies and their repercussions.

3. Psychosocial and occupational recommendations

(a) Specific aspects to be considered depending on the patient's psychological situation, family and social impact. Need for specific social support;

(b) Psychological approach. Fear of relapse;

(c) Recommendations about sexuality and contraception; 
(d) Recommendations about returning to work or resuming previous activities. Pursuing a life path/professional plan, and

(e) In certain women who want to be mothers, recommendations will be made about the best time to conceive. Young women who have preserved oocytes or ovarian cortex should be referred to Fertility Services at the Obstetrics and Gynecology Department.

Acknowledgements The authors would like to thank Fernando RicoVillademoros (COCIENTE SL, Madrid, Spain) for editorial assistance in the preparation of this manuscript.

\section{Compliance with ethical standards}

Funding This work has not received any funding.

Conflict of interest The authors declare no conflict of interest regarding this manuscript.

Research involving human participants and/or animals The manuscript does not contain clinical studies or patient data.

\section{Informed consent Not applicable.}

Open Access This article is distributed under the terms of the Creative Commons Attribution 4.0 International License (http://crea tivecommons.org/licenses/by/4.0/), which permits unrestricted use, distribution, and reproduction in any medium, provided you give appropriate credit to the original author(s) and the source, provide a link to the Creative Commons license, and indicate if changes were made.

\section{References}

1. Rojas MP, Telaro E, Russo A, Moschetti I, Coe L, Fossati R, et al. Follow up strategies for women treated for early breast cancer. Cochrane Database Sys Rev. 2005;25:CD001768.

2. National Institute for Clinical Excellence (2002). Guidance on Cancer Services: improving outcomes in breast cancer. Manual update. London: National Institute for Clinical Excellence. http://www.nice.org.uk/guidance/csgbc/evidence/ improving-outcomes-in-breast-cancer-manual-update-2.

3. Merck B, Vicente F, Clínico en Cáncer de Mama S. Manual de Práctica Clínica en Senología 2012. 2nd ed. Madrid: Fundación Española de Senología y Patología Mamaria; 2012. pp. 119-20.

4. Tellez de Peralta FJ. Seguimiento y control del cáncer de mama operado. In: Guías Clínicas de la Asociación Española de Cirujanos, Cirugía de la mama. Madrid: Ediciones Arán; 2006. pp. 326-333.

5. Khatcheressian JL, Hurley P, Bantug E, Esserman LJ, Grunfeld E, Halberg F, et al. Breast cancer follow-up and management after primary treatment: American Society of Clinical Oncology clinical practice guideline update. J Clin Oncol. 2013:31:961-5. doi:10.1200/JCO.2012.45.9859.

6. Arbona Rovira A, Martínez Lorenzo M, Fierro Barrabés G, Aguinaga Aizcorreta Ma T. Enfermería Oncológica. Unidad de Mama. Hospital de Día. Investigación Oncológica. Manual de Práctica Clínica en Senología 2012. 2nd ed Madrid: Fundación Española de Senología y Patología Mamaria; 2012. pp. 120-123.

7. Ferro T, Prades J. Necesidades de información en el cáncer de mama y de atención en la supervivencia. 1st ed. Barcelona: Federación Española de Cáncer de mama; 2013. http://fecma.vinagrero.es/documentos/LIBRONEC.pdf.

8. Feliu J, Virizuela JA. El seguimiento en los supervivientes de cáncer: una responsabilidad compartida. Med Clín. 2011;137:163-5. doi:10.1016/j.medcli. 2011.03.016.
9. Plan integral de atención a los largos supervivientes de cáncer. Sociedad Española de Oncología. Médica (SEOM). Madrid: Zentrum Verlagsgesellschaft.; 2013, pp 77-82.

10. Hidding JT, Beurskens CH, van der Wees PJ, van Laarhoven HW, Nijhuisvander Sanden MW. Treatment related impairments in arm and shoulder in patients with breast cancer: a systematic review. PLoS One. 2014;9:e96748. doi:10.1371/journal.pone.0096748.

11. Grunfeld E, Julian JA, Pond G, Maunsell E, Coyle D, Folkes A, et al. Evaluating survivorship care plans: results of a randomized, clinical trial of patients with breast cancer. J Clin Oncol. 2011;29:4755-62. doi:10.1200/JCO.2011.36.8373.

12. Donker M, van Tienhoven G, Straver ME, Meijnen P, van de Velde CJ, Mansel $\mathrm{RE}$, et al. Radiotherapy or surgery of the axilla after a positive sentinel node in breast cancer (EORTC 10981-22023 AMAROS): a randomised, multicentre, open-label, phase 3 non-inferiority trial. Lancet Oncol. 2014;15:1303-10. doi:10.1016/S1470-2045(14)70460-7.

13. Loren AW, Mangu PB, Beck LN, Brennan L, Magdalinski AJ, Partridge AH, et al. Fertility preservation for patients with cancer: American Society of Clinical Oncology clinical practice guideline update. J Clin Oncol. 2013;31:2500-10. doi:10.1200/JCO.2013.49.2678.

14. Azim HA, Davidson NE, Ruddy KJ. Challenges in treating premenopausal women with endocrine-sensitive breast cancer. Am Soc Clin Oncol Educ Book. 2016:35:23-32. doi:10.14694/EDBK_159069.

15. Braems G, Denys H, De Wever O, Cocquyt V, Van den Broecke R. Use of tamoxifen before and during pregnancy. Oncologist. 2011;16:1547-51. doi:10. 1634/theoncologist.2011-0121.

16. Runowicz CD, Leach CR, Henry NL, Henry KS, Mackey HT, Cowens-Alvarado $\mathrm{RL}$, et al. Recommendationsfor the follow-up care of female breast cancer survivors. J Clin Oncol. 2016;34:611-35. doi:10.1200/JCO.2015.64.3809.

17. Coleman R, Body JJ, Aapro M, Hadji P, Herrstedt J, ESMO Guidelines Working Group. Bone health in cancer patients: ESMO clinical practice guidelines. Ann Oncol. 2014;25(Suppl 3):iii124-37. doi:10.1093/annonc/mdu103.

18. Bentzen SM, Dische S. Morbidity related to axillary irradiation in the treatment of breast cancer. Acta Oncol. 2000;39:337-47. doi:10.1080/ 028418600750013113 .

19. Chlebowski RT, Blackburn GL, Thomson CA, Nixon DW, Shapiro A, Hoy MK, et al. Dietary fat reduction and breast cancer outcome: interim efficacy results from the Women's Intervention Nutrition Study. J Natl Cancer Inst. 2006;98:1767-76. doi:10.1093/jnci/djj494.

20. Ewer MS, Vooletich MT, Durand JB, Woods ML, Davis JR, Valero V, et al. Reversibility of trastuzumab-related cardiotoxicity: new insights based on clinical course and response to medical treatment. J Clin Oncol. 2005;23:7820-6. doi:10.1200/JCO.2005.13.300.

21. Cardinale D, Colombo A, Bacchiani G, Tedeschi I, Meroni CA, Veglia F, et al. Early detection of anthracycline cardiotoxicity and improvement with heart failure therapy. Circulation. 2015;131:1981-8. doi:10.1161/CIRCULATIO NAHA.114.013777.

22. Cardinale D, Biasillo G, Cipolla CM. Curing cancer, saving the heart: a challenge that cardioncology should not miss. Curr Cardiol Rep. 2016;18:51. doi:10. 1007/s11886-016-0731-z.

23. Curigliano G, Cardinale D, Dent S, Criscitiello C, Aseyev O, Lenihan D, et al. Cardiotoxicity of anticancer treatments: epidemiology, detection, and management. CA Cancer J Clin. 2016;66:309-25. doi:10.3322/caac.21341.

24. Zamorano JL, Lancellotti P, Rodriguez Muñoz D, Aboyans V, Asteggiano R, Galderisi M, et al. 2016 ESC Position Paper on cancer treatments and cardiovascular toxicity developed under the auspices of the ESC Committee for Practice Guidelines: the Task Force for Cancer Treatments and Cardiovascular Toxicity of the European Society of Cardiology (ESC). Eur Heart J. 2016:37:2768-801. doi:10.1093/eurheartj/ehw211.

25. Jagsi R, Griffith KA, Koelling T, Roberts R, Pierce LJ. Rates of myocardial infarction and coronary artery disease and risk factors in patients treated with radiation therapy for early-stage breast cancer. Cancer. 2007;109:650-7. doi:10. 1002/cncr.22452.

26. Darby SC, Ewertz M, McGale P, Bennet AM, Blom-Goldman U, Brønnum D, et al. Risk of ischemic heart disease in women after radiotherapy for breast cáncer. N Engl J Med. 2013;368:987-98. doi:10.1056/NEJMoa1209825.

27. Bower JE, Bak K, Berger A, Breitbart W, Escalante CP, Ganz PA, et al. Screening, assessment, and management of fatigue in adult survivors of cancer: an American Society of Clinical Oncology clinical practice guideline adaptation. J Clin Oncol. 2014;32:1840-50. doi:10.1200/JCO.2013.53.4495.

28. Deutsch M, Land SR, Begovic M, Wieand HS, Wolmark N, Fisher B. The incidence of lung carcinoma after surgery for breast carcinoma with and without postoperative radiotherapy. Results of National Surgical Adjuvant Breast and Bowel Project (NSABP) clinical trials B-04 and B-06. Cancer. 2003;98:1362-8. doi:10.1002/cncr.11655.

29. Karlsson P, Holmberg E, Samuelsson A, Johansson KA, Wallgren A. Soft tissue sarcoma after treatment for breast cancer-a Swedish population-based study. Eur J Cancer. 1998;34:2068-75. doi:10.1016/S0959-8049(98)00319-0. 